\title{
Yellow Nail Syndrome in Toenails
}

\author{
Takeshi Saraya $^{1}$, Rokuro Matsuoka ${ }^{2}$, Naoki Tsujimoto ${ }^{1}$ and Hajime Takizawa ${ }^{1}$
}

Key words: yellow nail syndrome, toenails, fingernails, slow growth

(Intern Med 54: 2089, 2015)

(DOI: 10.2169/internalmedicine.54.4875)
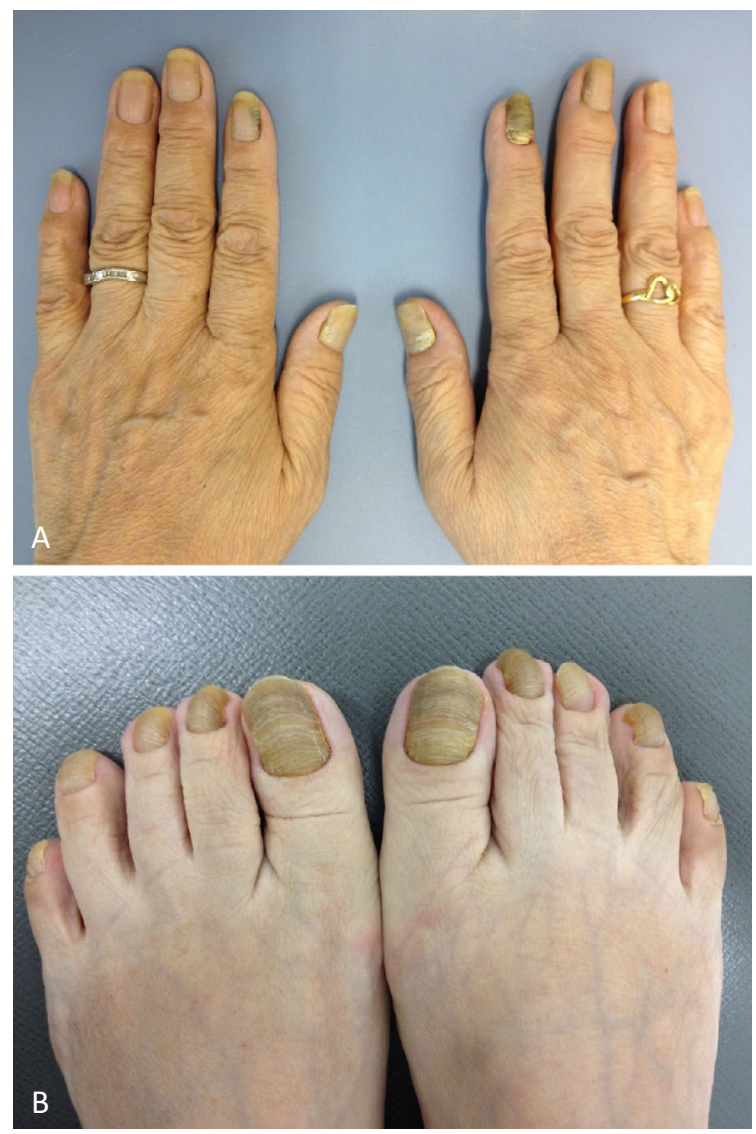

Picture.
A 64-year-old woman was referred to our respiratory department due to bronchiectasis. She had a previous medical history of Ramsay Hunt syndrome one year prior and had suffered from chronic sinusitis since childhood. She generally seemed to be in good physical condition, and the physical examination was normal except for slight lymphedema in the bilateral lower legs and yellow discoloration of the bilateral fingernails (Picture A) and toenails (Picture B). Of note, all of the patient's toenails were excessively curved and thickened and transverse ridging, similar to that observed in the fingernails, was visible. The patient's past medical history revealed that she first felt the slow growth of her toenails 5 years previously, while her fingernails started growing more slowly 3 years previously. Furthermore, for the past three months, she had not needed to clip her nails, thus suggesting interrupted nail growth. The patient was thus diagnosed to have yellow nail syndrome $(1,2)$ with the prominent symptoms first observed in her toenails.

The authors state that they have no Conflict of Interest (COI).

\section{References}

1. Samman PD, White WF. The "yellow nail" syndrome. Br J Dermatol 76: 153-157, 1964.

2. Maldonado F, Ryu JH. Yellow nail syndrome. Curr Opin Pulm Med 15: 371-375, 2009.

\footnotetext{
${ }^{1}$ Department of Respiratory Medicine, Kyorin Universitiy School of Medicine, Japan and ${ }^{2}$ Matsuoka Clinic, Japan Received for publication January 3, 2015; Accepted for publication January 13, 2015

Correspondence to Dr. Takeshi Saraya, sara@yd5.so-net.ne.jp

(C) 2015 The Japanese Society of Internal Medicine Journal Website: http://www.naika.or.jp/imonline/index.html
} 